form one composite list. This is then sent to all committee members, together with the CV questionnaires (but not the citations) shortly before the College's annual distinction awards meeting, usually held at the end of January.

The President chairs the meeting and its members consist of the honorary officers, two distinction awards advisers in each $\mathrm{NHS}$ region in England and Wales, the chairpersons of division, faculties and sections (if they have awards). Its task is to produce the College's final list of nominations from the composite lists produced by the regions, faculties, sections and honorary officers. The College Secretary and her personal assistant provide administrative support.

Only the names on the composite list of nominations are considered at the meeting and then only if the CV questionnaires and citations have been received in advance of the meeting. The Committee member who has made the nomination will speak briefly on behalf of each candidate. Some names are removed from the list at this stage. The Committee are given ample time to consider the paperwork, together with the relevant statistics, and finally to cast their votes.

The final list of College nominations is then submitted to the ACDA. Further information of the distinction awards procedures can be viewed at http:// www.doh.gov.uk/nhsexec/acda.htm

Vanessa Cameron Secretary, Royal College of Psychiatrists

\section{Eating Disorders in the UK: Policies for Service Development and Training}

\section{Council Report CR87}

\section{f7.50. 64 pp.}

With the collaboration of the Consumers Association, the Eating Disorders Special Interest Group surveyed specialist eating disorder services for adults in the UK, as a follow-up to a previous survey in 1991 Council Report CR14, Eating Disorders. We found that specialist services had increased in number since 1991 but that many areas remain without access to nearby specialist services. Many patients are sent long distances for specialist care, and adequate follow-up after such care is frequently impractical. Eating disorders are of high prevalence, representing a major source of morbidity, predominantly in young women, and the standardised mortality ratio of eating disorders is among the highest of all psychiatric disorders. There is a substantial evidence base for treatment of anorexia nervosa and bulimia nervosa, although research is urgently required to establish the most effective treatment for many groups of patients. We recommend the following action:

(a) For each area of the country, specialist services should be established, with one consultant psychiatrist per million population.

(b) These services should provide a combination of out-patient, inpatient and day patient services, with an appropriate range of therapeutic interventions.

(c) Expenditure on staffing should be approximately $\mathrm{f} 1$ per head of population.

(d) Steps should be taken to increase the number of consultant psychiatrists with special expertise in the assessment and treatment of eating disorders.

(e) Similar problems apply to the treatment of children and adolescents with eating disorders. Services for this group should be fully surveyed and recommendations developed for improving provision.

The Eating Disorders Special Interest Group has undertaken to develop criteria for specialist training in eating disorders in view of the particular mix of psychiatric, psychological, medical and nutritional problems faced by this severely ill group of patients. Our aim is to correct the unacceptable variation in care between different parts of the UK caused by unequal distribution of services.

Paul Robinson Chairman, Eating Disorders Special Interest Group

\section{Fitness to drive: The Driver and Vehicle Licensing Agency and the College}

Following a few high profile cases involving driving by people with both physical and mental disorders, the Driver and Vehicle Licensing Agency (DVLA) was asked by the Government of the time to review the procedures and standards to define fitness to drive. The new set of standards, as a result, was published in 1995 as the first issue of At a Glance (DVLA, 1995) and was sent to all practising doctors in the UK. Not surprisingly, the first issue covered controversial issues such as blanket withdrawal of the driving licence if someone had an episode of psychosis requiring in-patient hospital treatment. Justified or not, such restriction was in direct conflict with changes of policy, such as the emphasis on community care and closure of mental hospitals, thus placing more and more people with mental disorders in the community with an increased emphasis on social normalisation. Alongside this came changes to the benefit system that often influenced an individual's ability to afford to travel by public transport for social or clinical reasons. Such changes to the circumstances were occurring at a time of deregulation of buses, leading to a reduction of the level of service for remote and small communities.

The Public Policy Committee (PPC), from time to time, received notification of difficulties in patient care from College members as a result. It was clear that psychiatrists were representing individual cases directly to the DVLA, sometimes with satisfaction and sometimes not. Besides the perceived difficulties in clinical care some clinicians were concerned about a lack of clarity on whose responsibility it is to notify the DVLA regarding change to the physical and mental health of their patients.

With this background, the PPC agreed to explore the possibility of establishing a dialogue with the medical advisory department of the DVLA. The Honorary Secretary of the PPC visited the DVLA to attend the Secretary of State's advisory panel meeting and presented the College's concerns. During that visit it became very clear that:

(a) there was limited room for manoeuvre because the regulations that govern driving are approved by Parliament

(b) the DVLA's role is promulgation of these standards

(c) since the original publication, the standards have been refined and continue to be refined in the light of the experience

(d) such refinement was taking place through final approval by the Secretary of State upon receiving recommendations from the Advisory Panel.

The advisory panel on mental health matters was initially set up as a subgroup of the panel that dealt with drugs and alcohol related issues and held separate meetings. The psychiatric panel now stands alone. Currently, there exist six such advisory panels, which deal with the following areas:
(a) cardiology
(b) neurology
(c) diabetes
(d) vision
(e) alcohol/substance misuse
(f) psychiatry.

The psychiatric panel meets twice a year, including once in the autumn when the date for the next meeting is set.

The following documents outline the College's policy on driving related matters:

(a) Psychiatric standards of fitness to drive large goods vehicles (LGVs) and passenger carrying vehicles (PCVs) were published in the Psychiatric Bulletin in October 1993 (Royal College of Psychiatrists). 